\title{
Predictors of Positive or Close Surgical Margins in Breast-Conserving Surgery for Patients with Breast Cancer
}

\author{
Sang Min Hong*, Eun Young Kim, Kwan Ho Lee, Yong Lai Park, Chan Heun Park \\ Department of Surgery, Kangbuk Samsung Hospital, Sungkyunkwan University School of Medicine, Seoul, Korea
}

Purpose: This study aimed to determine the clinical and pathological factors associated with a higher rate of positive or close margins after breast-conserving surgery (BCS) by comparing these patients to patients with a negative margin. The second aim was to evaluate intraoperative resection margin status and reoperation rates for margin control in patients who underwent BCS. Methods: We reviewed the clinical and pathological data of all women diagnosed with invasive breast carcinoma (IBC) and ductal carcinoma in situ (DCIS) at our institution between January 2006 and December 2016. Results: During the 10-year study period, 785 patients were diagnosed with either IBC or DCIS, and 402 of these patients had undergone a total mastectomy as the primary treatment. The remaining 383 patients who underwent BCS were included in the final analysis. Of these, 100 patients (26.1\%) had intraoperative positive or close margins. The remaining 283 patients (73.9\%) had a negative margin intraoperatively, but 32 of these patients had positive or close margins on permanent sections. In the multivariate analyses, microcalcifications on mammograms (vs. none; odds ratio [OR], 1.911; 95\% confidence interval [Cl], 1.156-3.160), in situ carcinomas larger than $2.0 \mathrm{~cm}$ (vs. $\leq 2.0 \mathrm{~cm}$; OR, 3.106; 95\% Cl, 1.193-8.086), and lumpectomy (vs. quadrantectomy; OR, 2.863; 95\% Cl, 1.268-6.622) showed a significant association with a positive or close surgical margins. Patients with intraoperative positive or close margins underwent more reoperation than those with negative margins (5.0\% vs. $2.8 \%)$. Conclusion: After BCS, microcalcifications on mammograms, largesized in situ carcinomas, and lumpectomy were more likely to have positive or close margins.

Key Words: Breast neoplasms, Mastectomy, Reoperation

\section{INTRODUCTION}

Breast cancer is the most common malignancy in women and is the leading cause of death in Western industrialized countries [1]. Since the introduction of mammographic screening in the 1980s, the detection of nonpalpable, small-sized breast cancer has increased. The proportion of patients undergoing mastectomy has decreased, and now more patients are being treated with breast-conserving surgery (BCS) followed by breast irradiation. A randomized trial conducted 20 years of follow-up study to compare the efficacy and survival benefit of radical mastectomy to that of BCS [2]. The long-term survival rate of women undergoing BCS was equivalent to that of women undergoing radical mastectomy. Since these studies, BCS had become a standard treatment for women with relatively small-sized breast cancers as it offers

\section{Correspondence: Chan Heun Park}

Department of Surgery, Kangbuk Samsung Hospital, Sungkyunkwan University School of Medicine, 29 Saemunan-ro, Jongno-gu, Seoul 03181, Korea

Tel: +82-2-2001-1730, Fax: +82-2-2001-1883, E-mail: chanheun1@gmail.com

*These authors contributed equally to this work.

Received: Jan 4, 2018 Revised: Feb 16, 2018 Accepted: Apr 14, 2018 better cosmetic results and reduces the risk of infection.

Despite its cosmetic benefit and efficacy, a major drawback of BCS is the incidence of locoregional recurrence (LRR), even when combined with radiotherapy [3]. Ipsilateral breast tumor recurrence rate is estimated to be $5 \%-20 \%$ over 5-10-years' follow-up [4]. The patient's age, tumor size, positive lymph nodes, extensive intraductal component (EIC), lack of adjuvant systemic therapy, and dose and timing of radiotherapy are independent predictors of LRR. Among these factors, the pathologic margin status is the most important predictor $[5,6]$.

However, the definition of an adequate margin is still controversial. Some authors define negative margins as those being more than $1 \mathrm{~mm}$ [7], while others advocate margins of $10 \mathrm{~mm}$ or more [8]. Recurrence risk has been demonstrated to decrease proportionately with margin width, with the lowest recurrence rates in patients in whom a $10-\mathrm{mm}$ margin is achieved and the highest rates in patients with margins of less than $1 \mathrm{~mm}$ [9]. The National Comprehensive Cancer Network (NCCN) guideline and the 2014 Society of Surgical Oncology-American Society for Radiation Oncology Consensus Guidelines on Margins defines a negative margin in infiltrating carcinomas as having 
"no ink on the tumor" $[10,11]$. Cases with positive margins should undergo further surgery, such as re-excision or mastectomy. In select cases of microscopically focally positive margins in the absence of an EIC, the use of a higher radiation boost dose to the tumor bed could be considered. The definition of negative margins for ductal carcinoma in situ (DCIS) is somewhat different. The NCCN recommends that margins less than $1 \mathrm{~mm}$ are inadequate, and the American Society of Clinical Oncology guideline recommends a 2-mm margin as the standard for DCIS [12].

The key aim of this study was to determine the clinical and pathological factors associated with a higher rate of positive or close margins after BCS by comparing with a group of patients in whom a negative margin was achieved. The second aim was to evaluate the intraoperative resection margin status and the ratio of reoperation for margin control in patients who underwent BCS at our institution.

\section{METHODS}

\section{Patient selection}

This retrospective cohort study was conducted at the Department of Surgery, Kangbuk Samsung Hospital, and included all patients treated with a diagnosis of breast cancer between January 2006 and December 2016. Patients were selected by reviewing electronic medical charts for invasive breast carcinoma (IBC) and DCIS cases. From this population, only patients undergoing BCS as their first operation were included in the analysis.

\section{Surgery}

Two types of BCS were performed: (1) lumpectomy and (2) wide excision. The wide excision group consisted of either quadrantectomy or lumpectomy, with the superficial or deep margins of the excision extending up to the skin and pectoralis fascia, respectively (in this type of extended surgery, no re-excision was required if close or involved margins were superficial or deep). All nonpalpable lesions were wire-guided using ultrasound or mammography, and specimen radiography was performed to confirm the removal of microcalcifications. Specimens were marked with orienting sutures and sent to the pathology department for intraoperative evaluation of margin status.

\section{Pathologic and clinical evaluation}

Margin status was classified as positive when invasive or in situ disease were observed at the inked surgical margin, focally positive when the tumor focus was at the inked margin, close when tumor cells were $\leq 2 \mathrm{~mm}$ from the inked margin, and negative when tumor cells were $>2 \mathrm{~mm}$ from the inked margin [11]. When tumor cells were positive or close to the margin, the tumor was designated for re-excision. When the result was positive or close to the margin after three consecutive margin excisions, BCS was converted to mastectomy. Permanent sections were analyzed using paraffin-embedded blocks.

Patients were characterized based on their clinical characteristics: age at diagnosis; diagnostic method (i.e., core needle biopsy, excisional biopsy, stereotactic biopsy); palpability of the lesion; methods used for tumor localization (i.e., ultrasound, mammography, skin marking); presence of malignancy-related calcification; extensive microcalcifications; multifocality of the lesion; type of surgery (i.e., quadrantectomy, lumpectomy); locoregional recurrence; and distant metastasis and death from breast cancer. Patients were also characterized based on their pathological characteristics: histologic type; size of invasive or in situ carcinoma; grade of DCIS; tumor grade (Scarff-Bloom-Richardson grading modified by Elston and Ellis); number of metastatic lymph nodes; presence of in situ component; EIC; lymphovascular invasion; estrogen receptor (ER) status; progesterone receptor (PR) status; human epidermal growth factor receptor 2 (HER2) status; subtypes; 7th edition of the American Joint Committee on Cancer TNM stage; status of margins; and re-excision or secondary operation. The immunohistochemistry-defined subtypes were as follows: luminal A, ER(+) or PR(+), HER2(-); luminal B, ER(+) or PR(+), HER2(+); HER2enriched, ER(-) and PR(-), HER2(+); and triple-negative, ER(-) and PR(-), HER2(-) [13]. We further subtyped hormone receptor-positive tumors using the Ki-67 labeling index ( $<14 \%$ for luminal A vs. $\geq 14 \%$ for luminal B) to distinguish luminal B from luminal A tumors [14]. This study was approved by the institutional review boards (KBSMC 2014-10-008). Informed consent was obtained from all patients.

\section{Statistical analysis}

Student t-test for continuous variables and Pearson chi-square test for categorical variables were used to evaluate the associations between margin status and clinical and pathological characteristics. Univariate and multivariable logistic regression were used to calculate odds ratios 
Table 1. Clinicopathological characteristics of the study population

\begin{tabular}{|c|c|c|c|c|}
\hline Characteristic & $\begin{array}{c}\text { Total }(n=383) \\
\text { No. }(\%)\end{array}$ & $\begin{array}{l}\text { Positive or close margin }(n=132) \\
\text { No. }(\%)\end{array}$ & $\begin{array}{c}\text { Negative margin }(n=251) \\
\text { No. }(\%)\end{array}$ & $p$-value \\
\hline Age at diagnosis (yr)* & $49.97 \pm 10.36$ & $49.45 \pm 9.85$ & $50.24 \pm 10.64$ & 0.474 \\
\hline Age at diagnosis $(\mathrm{yr})^{\dagger}$ & & & & 0.332 \\
\hline$<50$ & $206(53.8)$ & $76(57.6)$ & $130(51.8)$ & \\
\hline$\geq 51$ & $177(46.2)$ & $56(42.4)$ & $121(48.2)$ & \\
\hline Method of diagnosis $^{\dagger}$ & & & & 0.116 \\
\hline Core needle biopsy & $332(86.7)$ & $117(88.6)$ & $215(85.7)$ & \\
\hline Excisional biopsy & $31(8.1)$ & $6(4.6)$ & $25(9.9)$ & \\
\hline Stereotactic biopsy & $20(5.2)$ & $9(6.8)$ & $11(4.4)$ & \\
\hline Palpability $^{\dagger}$ & $194(50.7)$ & $62(47.0)$ & $132(52.6)$ & 0.237 \\
\hline Type of wire-guided localization $^{\dagger}$ & & & & $<0.001$ \\
\hline Mammography & $27(7.0)$ & $14(10.6)$ & $13(5.2)$ & \\
\hline Ultrasound & $155(40.5)$ & $75(56.8)$ & $80(31.9)$ & \\
\hline None & $201(52.5)$ & $43(32.6)$ & $158(62.9)$ & \\
\hline Microcalcifications on mammogram ${ }^{\dagger}$ & $112(29.2)$ & $52(39.4)$ & $58(23.1)$ & 0.002 \\
\hline Extensive microcalcifications ${ }^{\ddagger}$ & $4(1.0)$ & $2(1.5)$ & $2(0.8)$ & 0.569 \\
\hline Multifocality ${ }^{\dagger}$ & $92(24.0)$ & $37(28.0)$ & $55(21.9)$ & 0.197 \\
\hline Size of invasive carcinoma $(\mathrm{cm})^{*}$ & $1.52 \pm 0.82$ & $1.52 \pm 0.80$ & $1.52 \pm 0.83$ & 0.999 \\
\hline Size of invasive carcinoma $(\mathrm{cm})^{\ddagger}$ & & & & 0.888 \\
\hline$\leq 2.0$ & $231(75.7)$ & $78(76.5)$ & $153(75.4)$ & \\
\hline$>2.0$ & $74(24.3)$ & $24(23.5)$ & $50(24.6)$ & \\
\hline Size of in situ carcinoma $(\mathrm{cm})^{*}$ & $1.76 \pm 0.98$ & $2.00 \pm 1.10$ & $1.61 \pm 0.87$ & 0.007 \\
\hline Size of in situ carcinoma $(\mathrm{cm})^{\ddagger}$ & & & & 0.002 \\
\hline$\leq 2.0$ & $144(65.8)$ & $46(53.5)$ & $98(73.7)$ & \\
\hline$>2.0$ & $75(34.2)$ & $40(46.5)$ & $35(26.3)$ & \\
\hline Histological tumor type $^{\dagger}$ & & & & 0.092 \\
\hline DCIS & $73(19.1)$ & $30(22.7)$ & $43(17.1)$ & \\
\hline IBC & $310(80.9)$ & $102(77.3)$ & $208(82.9)$ & \\
\hline Histological grade ${ }^{\dagger}$ & & & & 0.475 \\
\hline Low & $101(34.9)$ & $38(38.4)$ & $63(33.2)$ & \\
\hline Intermediate & $128(44.3)$ & $39(39.4)$ & $89(46.8)$ & \\
\hline High & $60(20.8)$ & $22(22.2)$ & $38(20.0)$ & \\
\hline Grade of DCIS ${ }^{\dagger}$ & & & & 0.046 \\
\hline Low & 47 (18.2) & $14(12.5)$ & $33(22.6)$ & \\
\hline Intermediate & $175(67.8)$ & $85(75.9)$ & $90(61.6)$ & \\
\hline High & $36(14.0)$ & $13(11.6)$ & $23(15.8)$ & \\
\hline No. of LN metastases* & $0.69 \pm 2.34$ & $0.53 \pm 1.60$ & $0.78 \pm 2.64$ & 0.244 \\
\hline Presence of in situ component ${ }^{\dagger}$ & $218(56.9)$ & $85(64.4)$ & $133(53.0)$ & 0.001 \\
\hline $\mathrm{EIC}^{+}$ & $30(7.8)$ & $12(9.1)$ & $18(7.2)$ & 1.000 \\
\hline $\mathrm{LVI}^{\dagger}$ & $45(11.7)$ & $18(13.6)$ & $27(10.8)$ & 0.398 \\
\hline ER positivity $^{\dagger}$ & $322(84.1)$ & $116(87.9)$ & $206(82.1)$ & 0.186 \\
\hline PR positivity ${ }^{\dagger}$ & $267(69.7)$ & $89(67.4)$ & $178(70.9)$ & 0.485 \\
\hline HER2 overexpression ${ }^{\ddagger}$ & $65(17.0)$ & $29(22.0)$ & $36(14.3)$ & 0.059 \\
\hline Tumor subtypes ${ }^{\ddagger}$ & & & & 0.081 \\
\hline Luminal $A$ & $233(62.5)$ & $81(61.3)$ & $152(63.1)$ & \\
\hline Luminal B & $77(20.6)$ & $35(26.5)$ & $42(17.4)$ & \\
\hline HER2 & $26(7.0)$ & $8(6.1)$ & $18(7.5)$ & \\
\hline Triple negative & $37(9.9)$ & $8(6.1)$ & $29(12.0)$ & \\
\hline T stage $^{\dagger}$ & & & & 0.640 \\
\hline 0 (in situ) & $77(20.1)$ & $30(22.7)$ & $47(18.7)$ & \\
\hline 1 & $237(61.9)$ & $81(61.4)$ & $156(62.2)$ & \\
\hline 2 & $67(17.5)$ & $21(15.9)$ & $46(18.3)$ & \\
\hline 3 & $2(0.5)$ & 0 & $2(0.8)$ & \\
\hline
\end{tabular}


Table 1. Continued

\begin{tabular}{|c|c|c|c|c|}
\hline Characteristic & $\begin{array}{c}\text { Total }(n=383) \\
\text { No. }(\%)\end{array}$ & $\begin{array}{l}\text { Positive or close margin }(n=132) \\
\text { No. }(\%)\end{array}$ & $\begin{array}{c}\text { Negative margin }(n=251) \\
\text { No. }(\%)\end{array}$ & $p$-value \\
\hline $\mathrm{N} \mathrm{stage}^{\dagger}$ & & & & 0.502 \\
\hline 0 & $296(77.7)$ & $104(80.0)$ & $192(76.5)$ & \\
\hline 1 & $62(16.3)$ & $20(15.4)$ & $42(16.7)$ & \\
\hline 2 & $18(4.7)$ & $6(4.6)$ & $12(4.8)$ & \\
\hline 3 & $5(1.3)$ & 0 & $5(2.0)$ & \\
\hline AJCC stage $^{\dagger}$ & & & & 0.161 \\
\hline 0 & $77(20.2)$ & $31(23.8)$ & $46(18.3)$ & \\
\hline I & $182(47.8)$ & $62(47.7)$ & $120(47.8)$ & \\
\hline II & $92(24.1)$ & $24(18.5)$ & $68(27.1)$ & \\
\hline III & $30(7.9)$ & $13(10.0)$ & $17(6.8)$ & \\
\hline Type of surgery $^{\ddagger}$ & & & & $<0.001$ \\
\hline Quadrantectomy & $178(46.5)$ & $41(31.1)$ & $137(54.6)$ & \\
\hline Lumpectomy & $205(53.5)$ & $91(68.9)$ & $114(45.4)$ & \\
\hline Locoregional recurrence $^{\ddagger}$ & $10(2.6)$ & $1(0.8)$ & $9(3.6)$ & 0.099 \\
\hline Distant metastasis $^{\ddagger}$ & $7(1.8)$ & $2(1.5)$ & $5(2.0)$ & 0.741 \\
\hline Death from breast cancer ${ }^{\ddagger}$ & $1(0.3)$ & 0 & $1(0.4)$ & 0.468 \\
\hline
\end{tabular}

Data are presented as number (\%) or mean \pm SD.

$\mathrm{DCIS}=$ ductal carcinoma in situ; IBC = invasive breast carcinoma; $\mathrm{LN}=$ lymph node; $\mathrm{EIC}=$ extensive intraductal component; $\mathrm{LVI}=$ lymphovascular invasion; $\mathrm{ER}=$ estrogen receptor; $\mathrm{PR}=$ progesterone receptor; $\mathrm{HER} 2$ = human epidermal growth factor receptor 2; $\mathrm{AJCC}=$ American Joint Committee on Cancer.

${ }^{*}$ Student t-test; ${ }^{\dagger}$ Pearson chi-square test; ${ }^{\ddagger}$ Fisher exact test.

(ORs) with 95\% confidence intervals (CIs) for positive or close margins. A p-value $<0.05$ (two-tailed) was considered statistically significant. All statistical analyses were performed using PASW Statistics for Windows, version 18.0 (SPSS Inc., Chicago, USA).

\section{RESULTS}

During the 10-year study period, 785 patients were diagnosed with either IBC or DCIS, and 402 of these patients had undergone a total mastectomy as the primary treatment. As a result, the remaining 383 patients who underwent BCS were included in the final analysis. Of these, 100 patients (26.1\%) had intraoperative positive or close margins. The remaining 283 patients $(73.9 \%)$ had a negative margin intraoperatively, but 32 of these patients had positive or close margins at permanent section. As a result, the positive or close margin group comprised 132 patients, and the negative margin group comprised 251 patients. During the study period, 310 IBC and 73 DCIS patients were evaluated. Among the 310 IBC patients, 284 were diagnosed with invasive ductal carcinoma, eight with invasive lobular carcinoma, and 18 with other types of carcinoma (i.e., tubular, mucinous, and micropapillary). The mean age was $49.9 \pm 10.3$ years (range, $20-85$ years), and the mean sizes of the IBC and DCIS tumors were $1.52 \mathrm{~cm}$ and $1.76 \mathrm{~cm}$, respectively.

\section{Comparison of clinicopathological characteristics between the positive or close margin and negative margin groups}

Patients who had positive or close margins were more likely to present with microcalcifications on their mammograms (39.4\% vs. $23.1 \%$, $p=0.002)$, large-sized in situ carcinomas (2.00 cm vs. $1.61 \mathrm{~cm}, p=0.007)$, and an in-situ component accompanied by IBC (64.4\% vs. 53.0\%, $p=$ 0.001). They were also more likely to undergo lumpectomy (68.9\% vs. $45.4 \%, p<0.001)$ than patients with a negative margin. A summary of clinical and pathological features is provided in Table 1.

\section{Univariate and multivariate analyses of predictors for a positive or close surgical margin}

In the univariate analysis, patients with wire-guided localization using mammography (vs. none; OR, 4.599; 95\% CI, 1.994-10.604), ultrasound (vs. none; OR, 4.003; 95\% CI, 2.485-6.449), microcalcifications on mammograms (vs. none; OR, 2.605; 95\% CI, 1.308-3.261), intermediate grade DCIS (vs. low; OR, 2.226; 95\% CI, 1.115-4.447), in situ carcinomas larger than $2.0 \mathrm{~cm}$ (vs. $\leq 2.0 \mathrm{~cm}$; OR, 2.435; 95\% CI, 1.373-4.319), the presence of an in situ component (vs. none; OR, 2.707; 
Table 2. Univariate and multivariate analyses of positive or close margin status

\begin{tabular}{|c|c|c|c|c|}
\hline \multirow{2}{*}{ Parameter } & \multicolumn{2}{|c|}{ Univariate } & \multicolumn{2}{|l|}{ Multivariate } \\
\hline & OR $(95 \% \mathrm{Cl})$ & $p$-value & $\mathrm{OR}(95 \% \mathrm{Cl})$ & $p$-value \\
\hline Age at diagnosis (yr) ( $\geq 51$ vs. $<50)$ & $0.792(0.518-1.211)$ & 0.281 & & \\
\hline \multicolumn{5}{|l|}{ Method of diagnosis } \\
\hline Excisional biopsy vs. core needle biopsy & $0.441(0.176-1.106)$ & 0.081 & $0.441(0.176-1.106)$ & 0.028 \\
\hline Stereotactic biopsy vs. core needle biopsy & $1.503(0.606-3.732)$ & 0.379 & $1.263(0.146-10.947)$ & 0.832 \\
\hline Palpability (yes vs. no) & $0.772(0.505-1.179)$ & 0.230 & & \\
\hline \multicolumn{5}{|l|}{ Type of wire-guided localization } \\
\hline Mammography vs. none & $4.599(1.994-10.604)$ & $<0.001$ & $3.586(0.393-32.698)$ & 0.002 \\
\hline Ultrasound vs. none & $4.003(2.485-6.449)$ & $<0.001$ & $4.033(1.687-9.641)$ & 0.257 \\
\hline Microcalcifications on mammogram (yes vs. no) & $2.605(1.308-3.261)$ & 0.002 & $1.911(1.156-3.160)$ & 0.012 \\
\hline Extensive microcalcifications (yes vs. no) & $1.762(0.245-12.654)$ & 0.574 & & \\
\hline Multifocality (yes vs. no) & $1.374(0.874-2.228)$ & 0.198 & & \\
\hline Size of invasive carcinoma $(\mathrm{cm})$ ( $>2.0$ vs. $\leq 2.0$ ) & $0.942(0.539-1.645)$ & 0.832 & & \\
\hline Size of in situ carcinoma $(\mathrm{cm})$ ( > 2.0 vs. $\leq 2.0$ ) & $2.435(1.373-4.319)$ & 0.002 & $3.106(1.193-8.086)$ & 0.020 \\
\hline Histological tumor type (IBC vs. DCIS) & $0.654(0.385-1.111)$ & 0.116 & & \\
\hline \multicolumn{5}{|l|}{ Histological grade } \\
\hline Intermediate vs. low & $0.726(0.419-1.261)$ & 0.256 & & \\
\hline High vs. low & $0.960(0.495-1.860)$ & 0.903 & & \\
\hline \multicolumn{5}{|l|}{ Grade of DCIS } \\
\hline Intermediate vs. low & $2.226(1.115-4.447)$ & 0.023 & $2.961(0.853-10.276)$ & 0.087 \\
\hline High vs. low & $1.332(0.529-3.356)$ & 0.543 & $1.021(0.178-5.872)$ & 0.981 \\
\hline LN metastasis (yes vs. no) & $0.946(0.845-1.058)$ & 0.327 & & \\
\hline Presence of in situ component (yes vs. no) & $2.707(1.494-4.905)$ & 0.001 & $\mathrm{~N} / \mathrm{A}$ & \\
\hline EIC (yes vs. no) & $0.963(0.442-2.097)$ & 0.924 & & \\
\hline LVI (yes vs. no) & $1.333(0.695-2.558)$ & 0.387 & & \\
\hline ER positive (yes vs. no) & $1.584(0.857-2.927)$ & 0.142 & & \\
\hline PR positive (yes vs. no) & $0.849(0.539-1.337)$ & 0.480 & & \\
\hline HER2 overexpression (yes vs. no) & $1.681(0.977-2.893)$ & 0.060 & & \\
\hline \multicolumn{5}{|l|}{ Tumor subtypes } \\
\hline Luminal B vs. luminal A & $1.564(0.927-2.639)$ & 0.094 & & \\
\hline HER2 overexpression vs. luminal A & $0.834(0.348-2.001)$ & 0.684 & & \\
\hline Triple negative vs. luminal A & $0.518(0.226-1.185)$ & 0.119 & & \\
\hline \multicolumn{5}{|l|}{ Tstage } \\
\hline T1 vs. Tis & $0.813(0.478-1.383)$ & 0.446 & & \\
\hline T2 vs. Tis & $0.715(0.359-1.426)$ & 0.341 & & \\
\hline T3 vs. Tis & N/A & & & \\
\hline \multicolumn{5}{|l|}{ N stage } \\
\hline N1 vs. N0 & $0.879(0.490-1.576)$ & 0.665 & & \\
\hline N2 vs. N0 & $0.923(0.337-2.531)$ & 0.876 & & \\
\hline N3 vs. N0 & $\mathrm{N} / \mathrm{A}$ & & & \\
\hline \multicolumn{5}{|l|}{ AJCC stage } \\
\hline Ivs. 0 & $0.767(0.443-1.327)$ & 0.343 & $6.096(0.562-66.155)$ & 0.137 \\
\hline II vs. 0 & $0.524(0.273-1.004)$ & 0.052 & $2.086(0.171-25.385)$ & 0.564 \\
\hline III vs. 0 & $1.135(0.486-2.665)$ & 0.772 & $4.923(0.360-67.394)$ & 0.232 \\
\hline Type of surgery (lumpectomy vs. quadrantectomy) & $2.667(1.710-4.161)$ & $<0.001$ & $2.863(1.268-6.622)$ & 0.014 \\
\hline
\end{tabular}

Values are number of individuals, $\mathrm{n}(\%)$ or mean $\pm \mathrm{SD}$.

$\mathrm{OR}=$ odds ratio; $\mathrm{Cl}=$ confidence interval; $\mathrm{IBC}=$ invasive breast carcinoma; $\mathrm{DCIS}=$ ductal carcinoma in situ; $\mathrm{LN}=$ lymph node; $\mathrm{N} / \mathrm{A}=$ not applicable; $\mathrm{ElC}=$ extensive intraductal component; $\mathrm{LVI}=$ lymphovascular invasion; $\mathrm{ER}=$ estrogen receptor; $\mathrm{PR}=$ progesterone receptor; $\mathrm{HER} 2=$ human epidermal growth factor receptor 2; AJCC = American Joint Committee on Cancer.

95\% CI, 1.494-4.905), and lumpectomy (vs. quadrantectomy; OR,

2.667; 95\% CI, 1.710-4.161) showed a significant association with a positive or close surgical margin (Table 2).

In the multivariate analysis, microcalcifications on mammograms 


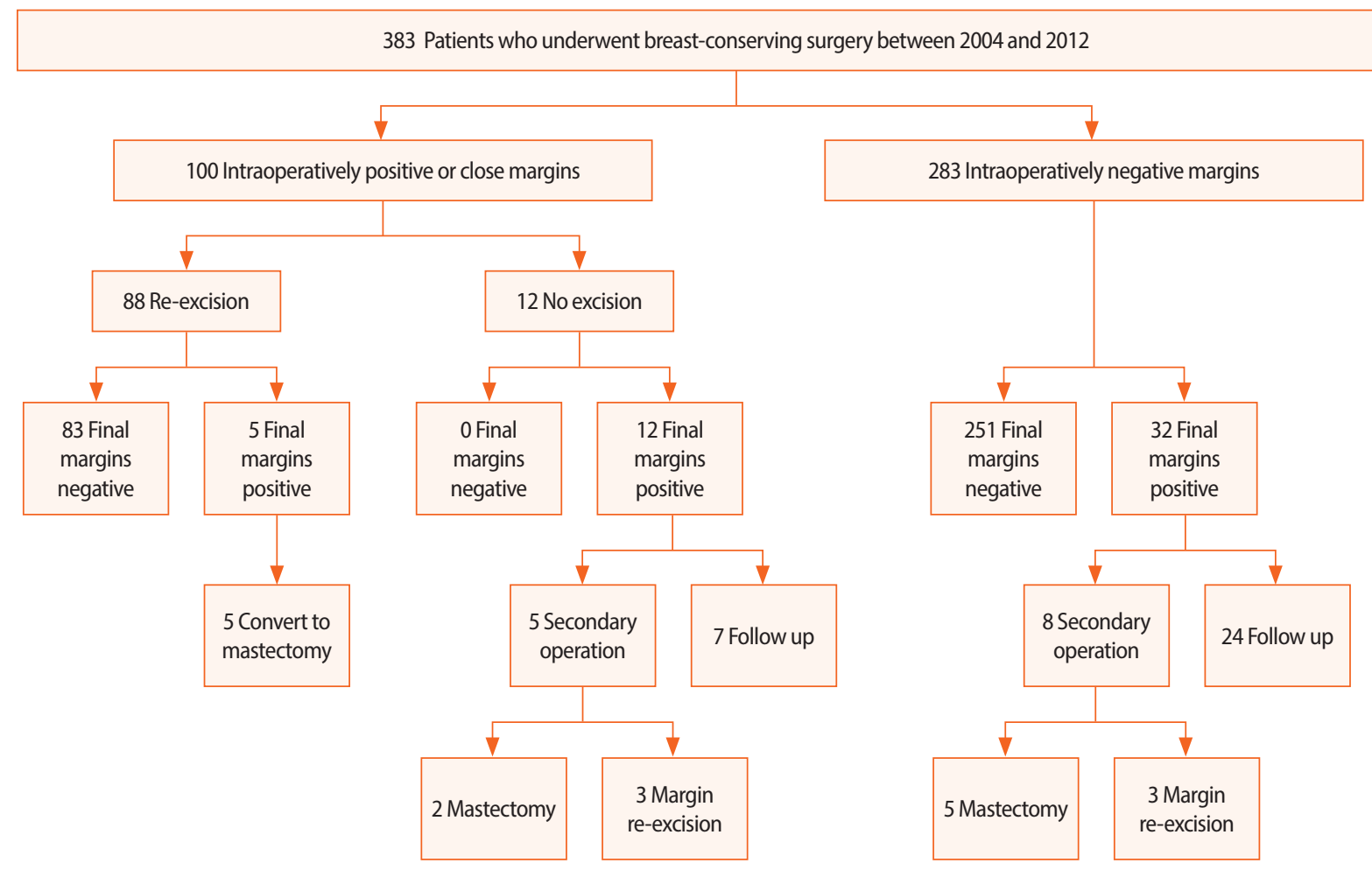

Figure 1. Diagram of patients in the study cohort.

(vs. none; OR, 1.911; 95\% CI, 1.156-3.160), in situ carcinomas larger than $2.0 \mathrm{~cm}$ (vs. $\leq 2.0 \mathrm{~cm}$; OR, 3.106; 95\% CI, 1.193-8.086), and lumpectomy (vs. quadrantectomy; OR, 2.863; 95\% CI, 1.268-6.622) showed a significant association with a positive or close surgical margin (Table 2).

\section{Intraoperative margin assessment and decisions regarding re-excision}

The results of the intraoperative margin assessment, re-excision rate analysis, and final margin assessment are shown in Figure 1. While 100 patients (26.1\%) were found to have positive or close margins on intraoperative evaluation, 88 of them underwent re-excision of the involved margin during the same operation. All except five patients achieved a final negative margin. These remaining five patients had three consecutive positive or close margins, and a total mastectomy was ultimately performed. Twelve patients with intraoperative positive or close margins did not undergo re-excision but instead planned to be re-evaluated during the permanent section analysis. Permanent margin status was positive for all 12 patients. Only five of the $12 \mathrm{pa}-$ tients underwent a secondary operation (total mastectomy, 2; margin re-excision, 3). The remaining seven patients did not undergo re-exci- sion because the directions of the positive or close margins were superficial or deep so that there was no remaining breast tissue. These patients were treated with boost radiation therapy, and no recurrences were reported during the 10-year follow-up period. Among $100 \mathrm{pa}-$ tients with intraoperative positive or close margins, five (5.0\%) underwent secondary operations. Among 283 patients with intraoperative negative margins, eight (2.8\%) underwent secondary operations. Patients with intraoperative positive or close margins underwent more reoperation than those with negative margins (5.0\% vs. $2.8 \%$ ).

\section{Final margin assessment and decisions regarding re-excision}

Thirty-two patients (8.3\%) had negative margins on intraoperative assessment but positive margins on permanent pathologic evaluation. Among this population, eight patients underwent a secondary operation (total mastectomy, 5; margin re-excision, 3). The remaining 24 patients did not undergo a secondary operation because the direction of the positive or close margins was superficial or deep so that there was no remaining breast tissue. These patients were treated with boost radiation therapy, and no recurrences were reported during the 10-year follow-up period. 


\section{DISCUSSION}

After BCS, the LRR rate ranges from 5\% to $20 \%$ after 5-10 years [4]. Many risk factors of LRR are known, such as the age at diagnosis, tumor size, lymph node metastasis, EIC, adjuvant systemic therapy, the amount and initiation date of radiation therapy, and the free margin status during operation. The status of the surgical margins is the most important factor, as it directly affects the risk of recurrence $[5,6]$. Since the National Surgical Adjuvant Breast and Bowel Project first introduced the importance of margin status in 1989, the rate of local recurrence has decreased, and the overall survival rate for BCS has become comparable to that of mastectomy [15]. However, there is currently no clear indication for positive or close margins. The definition of a positive margin varies, such that cancer cells can be from 1 to $5 \mathrm{~mm}$ from the margin $[7,16]$.

Our findings revealed that wire-guided localization using mammography and ultrasound, microcalcifications on mammograms, an intermediate grade of DCIS, large-sized in situ carcinomas, the presence of an in-situ component accompanied by IBC, and lumpectomy were associated with positive or close margins after BCS. Several researchers have reported predictors of margin positivity and re-excision [17]. Tumor size, nodal positivity, multifocality, EIC, lobular histology, and young age were often regarded as significant factors [16].

In our study, we found that the likelihood of a positive or close margin was increased for large-sized $(>2.0 \mathrm{~cm})$ in situ carcinomas. In situ components accompanied by IBC and microcalcifications on mammograms also correlated with positive or close margin status in univariate analysis (Table 2). Based on these results, it is essential to detect the presence of in situ components at the surgical margin during intraoperative frozen biopsies. Intraoperative specimen mammography is also essential for confirming the retrieval of microcalcifications and thereby reducing the chance of positive margins. However, the margin of DCIS is not well defined, and the extension into breast tissue is often difficult to determine, which results in a high rate of reoperation [18]. The rate of reoperation owing to positive margins was twice as high when tumors had an in situ component [19]. The presence of microcalcifications is another factor that makes it difficult to interpret margin status. Therefore, patients with microcalcifications on preoperative mammograms should be identified for margin positivity and secondary operation.
Wire-guided localization using either mammography or ultrasound is the standard technique for locating tumors before surgery for nonpalpable breast cancers. However, it is more difficult to achieve negative margins in nonpalpable lesions due to technical factors and the diversity in its radiographic appearance [20]. The wire can be displaced, leading to an inaccurate localization, or it can be transected during surgery [21]. For these reasons, we also found a likelihood of positive or close margins with ORs of 4.599 and 4.003 for wire-guided localization using mammography and ultrasound, respectively. A recent study reported intraoperative wire-guided localization using ultrasound in BCS to decrease positive margin status and improve assessment of margin status [22]. Further studies are needed to assess the validity of wire-guided localization in terms of positive or close margins.

There are two types of BCS. It is assumed that wide excision may be superior in terms of local radicality, and lumpectomy may be better in terms of cosmetic outcome [23]. Currently, there are few studies comparing quadrantectomy and lumpectomy regarding disease control outcomes, such as LRR or distant metastasis. However, some have reported no significant difference in ipsilateral breast tumor recurrence between quadrantectomy and lumpectomy if adequate surgical margins could be achieved [23]. Quadrantectomy removes the entire quadrant of the breast containing the primary tumor with overlying skin and the fascia of the major pectoralis muscle and was first described by Veronesi et al. [24]. Lumpectomy completely excises the lesion with at least $1 \mathrm{~cm}$ of tissue around the clinical margin of the tumor [25]. We found that lumpectomy, compared to wide excision, increased the likelihood of positive or close margins. Consistent with our result, Ramanah et al. [26] also showed that quadrantectomy decreased the rate of re-excision. However, others found that when close or involved margins were superficial and deep, re-excision showed no residual tumor [27]. Therefore, further discussions are necessary to determine the appropriate surgery to decrease positive or close margins. Surgeons also need to explain to patients with large-size $(>2.0 \mathrm{~cm})$ in situ carcinoma who are initially scheduled to undergo lumpectomy that the possibility of resecting larger margins than planned and converting to wide excision exists.

To avoid positive or close margin status after BCS, a high accuracy of intraoperative frozen section analysis (FSA) is required. Freezing tissues in a glycol-based polyethylene-embedding compound can be 
performed in a relatively short period intraoperatively, yielding an accuracy of $97 \%$ with sensitivity and specificity rates between $95 \%$ and 99\% [28]. However, the relatively high false negative rate of FSA or the number of two-stage procedures, due to discrepancies between FSA and the final pathological report, reportedly ranges from $0 \%$ to $19 \%$ [29]. New methods for intraoperative margin assessment, such as hand-held positron emission tomography probes or the radio-guided occult lesion localization method, have been introduced to overcome this limitation [30].

In conclusion, we have confirmed that wire-guided localization using mammography and ultrasound, the presence of microcalcifications on mammograms, large-sized in situ carcinomas, the presence of an in-situ component accompanied by IBC, and lumpectomy increased the likelihood of positive or close margins after BCS. Patients with these factors should be considered for and advised about the need for further surgery. A multidisciplinary team approach should also be applied to decrease the chance of positive or close margins and achieve effective local control.

\section{CONFLICT OF INTEREST}

The authors declare that they have no competing interests.

\section{REFERENCES}

1. Heron M. Deaths: leading causes for 2004. Natl Vital Stat Rep 2007; 56:1-95.

2. Veronesi U, Cascinelli N, Mariani L, Greco M, Saccozzi R, Luini A, et al. Twenty-year follow-up of a randomized study comparing breastconserving surgery with radical mastectomy for early breast cancer. N Engl J Med 2002;347:1227-32.

3. Renton SC, Gazet JC, Ford HT, Corbishley C, Sutcliffe R. The importance of the resection margin in conservative surgery for breast cancer. Eur J Surg Oncol 1996;22:17-22.

4. Meric F, Mirza NQ, Vlastos G, Buchholz TA, Kuerer HM, Babiera GV, et al. Positive surgical margins and ipsilateral breast tumor recurrence predict disease-specific survival after breast-conserving therapy. Cancer 2003;97:926-33.

5. Smitt MC, Nowels K, Carlson RW, Jeffrey SS. Predictors of reexcision findings and recurrence after breast conservation. Int J Radiat
Oncol Biol Phys 2003;57:979-85.

6. Mirza NQ, Vlastos G, Meric F, Buchholz TA, Esnaola N, Singletary SE, et al. Predictors of locoregional recurrence among patients with early-stage breast cancer treated with breast-conserving therapy. Ann Surg Oncol 2002;9:256-65.

7. Cheng L, Al-Kaisi NK, Gordon NH, Liu AY, Gebrail F, Shenk RR. Relationship between the size and margin status of ductal carcinoma in situ of the breast and residual disease. J Natl Cancer Inst 1997; 89:1356-60.

8. Neuschatz AC, DiPetrillo T, Steinhoff M, Safaii H, Yunes M, Landa $\mathrm{M}$, et al. The value of breast lumpectomy margin assessment as a predictor of residual tumor burden in ductal carcinoma in situ of the breast. Cancer 2002;94:1917-24.

9. Silverstein MJ, Lagios MD, Groshen S, Waisman JR, Lewinsky BS, Martino S, et al. The influence of margin width on local control of ductal carcinoma in situ of the breast. N Engl J Med 1999;340:145561.

10. NCCN clinical practice guidelines in oncology, version 2. National Comprehensive Cancer Network. https://www.nccn.org/professionals/ default.aspx. Accessed June 1st, 2016.

11. Moran MS, Schnitt SJ, Giuliano AE, Harris JR, Khan SA, Horton J, et al. Society of Surgical Oncology-American Society for Radiation Oncology consensus guideline on margins for breast-conserving surgery with whole-breast irradiation in stages I and II invasive breast cancer. J Clin Oncol 2014;32:1507-15.

12. Morrow M, Van Zee KJ, Solin LJ, Houssami N, Chavez-MacGregor M, Harris JR, et al. Society of Surgical Oncology-American Society for Radiation Oncology-American Society of Clinical Oncology consensus guideline on margins for breast-conserving surgery with whole-breast irradiation in ductal carcinoma in situ. Pract Radiat Oncol 2016;6:287-95

13. Dai X, Li T, Bai Z, Yang Y, Liu X, Zhan J, et al. Breast cancer intrinsic subtype classification, clinical use and future trends. Am J Cancer Res 2015;5:2929-43.

14. Cheang MC, Chia SK, Voduc D, Gao D, Leung S, Snider J, et al. Ki67 index, HER2 status, and prognosis of patients with luminal B breast cancer. J Natl Cancer Inst 2009;101:736-50.

15. Fisher ER, Sass R, Fisher B, Gregorio R, Brown R, Wickerham L. Pathologic findings from the National Surgical Adjuvant Breast Project (protocol 6). II. Relation of local breast recurrence to multi- 
centricity. Cancer 1986;57:1717-24.

16. Dillon MF, Hill AD, Quinn CM, McDermott EW, O’Higgins N. A pathologic assessment of adequate margin status in breast-conserving therapy. Ann Surg Oncol 2006;13:333-9.

17. Luu HH, Otis CN, Reed WP Jr, Garb JL, Frank JL. The unsatisfactory margin in breast cancer surgery. Am J Surg 1999;178:362-6.

18. Talsma AK, Reedijk AM, Damhuis RA, Westenend PJ, Vles WJ. Re-resection rates after breast-conserving surgery as a performance indicator: introduction of a case-mix model to allow comparison between Dutch hospitals. Eur J Surg Oncol 2011;37:357-63.

19. Jeevan R, Cromwell DA, Trivella M, Lawrence G, Kearins O, Pereira J, et al. Reoperation rates after breast conserving surgery for breast cancer among women in England: retrospective study of hospital episode statistics. BMJ 2012;345:e4505.

20. Lovrics PJ, Cornacchi SD, Vora R, Goldsmith CH, Kahnamoui K. Systematic review of radioguided surgery for non-palpable breast cancer. Eur J Surg Oncol 2011;37:388-97.

21. McGhan LJ, McKeever SC, Pockaj BA, Wasif N, Giurescu ME, Walton HA, et al. Radioactive seed localization for nonpalpable breast lesions: review of 1,000 consecutive procedures at a single institution. Ann Surg Oncol 2011;18:3096-101.

22. Slijkhuis WA, Noorda EM, van der Zaag-Loonen H, Eenennaam MJ, Greve KE, Lastdrager WB, et al. Ultrasound-guided breast-conserving surgery for early-stage palpable and nonpalpable invasive breast cancer: decreased excision volume at unchanged tumor-free resection margin. Breast Cancer Res Treat 2016;158:535-41.
23. Noh WC, Paik NS, Kim MS, Yang KM, Cho CK, Choi DW, et al. Ipsilateral breast tumor recurrence after breast-conserving therapy: a comparison of quadrantectomy versus lumpectomy at a single institution. World J Surg 2005;29:1001-6.

24. Veronesi U, Banfi A, Saccozzi R, Salvadori B, Zucali R, Uslenghi C, et al. Conservative treatment of breast cancer: a trial in progress at the Cancer Institute of Milan. Cancer 1977;39(6 Suppl):2822-6.

25. Veronesi U, Volterrani F, Luini A, Saccozzi R, Del Vecchio M, Zucali $\mathrm{R}$, et al. Quadrantectomy versus lumpectomy for small size breast cancer. Eur J Cancer 1990;26:671-3.

26. Ramanah R, Pivot X, Sautiere JL, Maillet R, Riethmuller D. Predictors of re-excision for positive or close margins in breast-conservation therapy for pT1 tumors. Am J Surg 2008;195:770-4.

27. Dooley WC, Parker J. Understanding the mechanisms creating false positive lumpectomy margins. Am J Surg 2005;190:606-8.

28. Ferreiro JA, Gisvold JJ, Bostwick DG. Accuracy of frozen-section diagnosis of mammographically directed breast biopsies: results of 1,490 consecutive cases. Am J Surg Pathol 1995;19:1267-71.

29. Sauter ER, Hoffman JP, Ottery FD, Kowalyshyn MJ, Litwin S, Eisenberg BL. Is frozen section analysis of reexcision lumpectomy margins worthwhile? Margin analysis in breast reexcisions. Cancer 1994;73: 2607-12.

30. Strong VE, Humm J, Russo P, Jungbluth A, Wong WD, Daghighian F, et al. A novel method to localize antibody-targeted cancer deposits intraoperatively using handheld PET beta and gamma probes. Surg Endosc 2008;22:386-91. 